\title{
National and State Classical University in a Globalizing Modernity
}

\author{
Konstantin Maltsev * Artem Alaverdyan, and Anni Maltseva \\ Belgorod State Technological University named after V.G. Shukhov, 308012 Belgorod, Russia
}

\begin{abstract}
The classical "university of reason", the idea of which is defined in German classical philosophy and German romanticism as "preparation for knowledge", and "mission" - as "the formation of goodwill", i.e. the education of a citizen, has lost its foundation in modernity: the essential unity of culture, the nation, the state, and the university is removed and the named "elements" of this unity in modern reality, presented in the liberal version of the economic paradigm, mean something else: the article indicates their new meaning, and as such are no longer connected. The thing that has replaced the "university of reason" in modernity has other tasks: to guarantee globalization by producing technical, i.e. directly useful and standardized knowledge, and to participate in the formation of human capital. The products produced by the university are offered on the global market as a competitively priced commodity; the name "university" is still kept as a "technical term" to denote a "bureaucratically and commercially oriented corporation". (B. Ridings). At the same time, a unified educational space as one of the areas of the global order needs the formation of a cosmopolitan worldview - the structure, the content of educational programs, the form of organization of the modern university-corporation (as now - "multicultural reality") are aimed at fulfilling such a definite task. The concept of "sustainable development" and its stated agenda, by defining educational goals, represents a way of 'politicizing' (W. Beck), which aims to limit total market logic and balance necessary inequalities to ensure the unity of the global order; the article asks what this means for a university that has lost its essential identity and is embedded in a global network.
\end{abstract}

\section{Introduction}

Since the mid-1970s, the concept of "sustainable development" has focused on a global order that appears hierarchically structured as one center and several peripheries assigned different functions in a single system. Education is seen as an area of the global order, to which its structure is transposed: shared principles and standards - and the different tasks assigned to institutions to implement a common global "education space". It is primarily and explicitly about the difference of capabilities related to the availability and willingness to "make available", the necessary resources (material, infrastructural, human). Still, it is

\footnotetext{
*Corresponding author: maltsevaannav@mail.ru
} 
necessary to keep the goal, which was defined when the concept of sustainable development was created: the hierarchical structure, the relationship "center-periphery", should be maintained and ensured in its preservation.

The classical university was essentially "national" and "state", its idea as defined by German Romantics I.G. Fichte [1] and W. von Humboldt [2], included "national" and "state" not as an "external", "accidental" or "transitory" requirement, but as internal, necessary development of the essence of the idea itself. Obviously, there is no more room for this idea in the globalizing modernity, the global order, and, in particular, the global educational space: the university must be reformed or, if this proves impossible, replaced by something else, which may also be called, but now only as a "technical term" (G.G. Gadamer [3]). Apparently, it was the second option that became a reality, despite the public rhetoric about "preserving continuity", "improving" and other things of the same sort - the usual way to conduct and legitimize a radical "innovation" in "public" and "expert" opinion. The fulfillment of this task concerning the university is facilitated by the fact that it is the idea that is replaced: to understand it, one needs philosophy - and, according to Heidegger, "the simplest philosophical knowledge in the epoch of the completed New Age is the knowledge that and why philosophy had to become impossible and remains unnecessary for this epoch" [4, p. 431].

The aims of this paper are: to demonstrate the gap between the idea of the classical university and the idea of the modern university; to clarify the meaning of the said gap as construed in the horizon of globalization; and, finally, to find the direction in which the name (name) of the "phenomenon of modernity" is found, for which the name "university" is still reserved, as we said, as a technical term only. The set tasks' solution aims to answer the question: how - instrumentally or essentially - the "new university" fits into the concept of sustainable development, and what meaning is defined in its context to the "innovative university".

\section{Research Methodology}

The subject of the article is the idea (of the classical university) and the idea (of the modern innovative university), the certainty of which follows from the understanding of globalization as "the dominant of modernity" (in the words of, for example, W. Beck [5] as a necessary, inevitable, objective process). Understanding an idea and discovering the meaning of a representation is possible through what Gadamer called philosophical hermeneutics. But it is also a question of reality, in the explanation of which the Weberian distinction between "attribution to value" and "evaluation" must be strictly observed; whatever our attitude to what is going on, it must be isolated (A. Schütz [6], for example) and, as far as possible, to "not participate" in forming judgments about the reality we are considering; but since evaluation cannot be excluded altogether, one should strive for clarity: where and why one cannot do without evaluations - obviously, what is meant here is the direction in which the research is going, and the relation between the different causal sequences built up to explain them. Thus, understanding (philosophy) and explanation (positive disciplinary science) are equally necessary for the task at hand - but the immediate subject matter and the way it is thematized suggest the priority of philosophical interpretation.

\section{Findings}

The idea of the classical university [7] was created in German classical philosophy and German romanticism in the horizon of the Kantian notion of the subject and subjectivity: as 
a "university of reason" and "preparation for knowledge"; but the absolute subject not only supposes the reality of the self as reasonable but in its representation we find what is called the world: we deal with the process of the unfolding of subjectivity as reality. Culture, nation, and state were believed to be necessary forms of this process. The university, which, according to Fichte, was supposed to "shape the will" of the subject toward the good, was thus thought of as a place where not only knowledge grows and a corporation of professors trains students who are to succeed in maintaining said growth, but it educates a citizen who consciously and freely identifies with his cultural and national identity and with his state. Thus, the idea and mission of the university are defined; it should be demonstrated how it was represented by the classical university.

Fichte's concept of national identity is based on the Kantian concept of an autonomous free, i.e. self-determining, subject [8], the initial spontaneity of which required, for its implementation, a framework: in fact, in this case, we are talking about the usual for German philosophy concept of becoming, which as self-sufficiency, it assumes the fixation of what has become; everyone has the right to develop freely from himself: the individual development of everyone (and nation and culture were considered as "individuals") is a condition for achieving excellence.

Spontaneity is intrinsic only to one who can preserve "the self," i.e. to repeat, it is "of itself" the freedom of the self-determined subject. The means by which one becomes aware of one's identity is language, which, among other things, unites free individuals into a cultural unity. Language is "the place of myth", the main thing that unites in a nation (culture, history are essentially mythical); but to "keep the myth", language must be primordial, that is not corrupted by "external influences": Fichte distinguishes between primordial and derived languages: only primordial language defines the limits of true culture. A nation is called every genuine culture that has become "for itself", i.e. that has become conscious of its own specialness and is realized within its boundaries, when "people living together and continuing to form their language in uninterrupted communication, on whose linguistic means the same external influences are exercised, are called a people" [1, 113]. National, cultural, linguistic boundaries in this view are the same, differing not in essence, but in the "angle of view" on them; such boundaries are both natural and fair; both "from the inside" and "from the outside" these are state boundaries: language, culture, nation, state, - sequential forms that fix the spontaneity of the individual, which is in the process of implementation; the state is the full realization of the freedom of the individual, the "march of God on earth", "the realization of a moral idea" is not an "arbitrary statement" forced by "the force of external circumstances", but the very essence; moreover, Fichte connects the "perfect state" with the tasks of education: "Only that nation that first solves the task of educating a perfect person through actual implementation can then create a perfect state $[1,160]$; we are talking about both the right to the state and the duty: simply because outside of this "form" the nation "ceases to be", and "is forced to unite with the conquerors", followed by "complete oblivion of relations that no longer exist" [ 1, p. 69].

An essential difference in the German classical understanding of the freedom of the self-determined individual is that for German philosophers, beginning with Kant, such freedom was not only a "right" (with a bias towards arbitrariness) defined through interest, but an obligation, i.e. a necessity, defined through the essence of subjectivity; in this respect, Hegel's position on "freedom as a realized necessity" (i.e., as "freedom for itself") is not only sound ("true"). Still, it is better understood through Hegel's own statement on "wonder as a challenge to my freedom".

Thus, the essential connection and order (structure) linking the state, culture, and nation is found in the subject, and it's free (spontaneous) self-determination; the connection we study lacks one more necessary link in any representation of the unity understudy - the 
university. Fichte himself argues that education is "the key to power" and, above all, in its "transformation" is "the only means of preserving the German nation." According to Fichte, "the new education must be able to reliably and unmistakably, guided by the rules, educate and determine the real-life motives and movements of its pupils [1, 70], i.e. the philosopher simultaneously states that one should "educate man himself and make education in no way property of the pupil as hitherto, but rather a component of his personality [1, 65], and: "We intend employing new education to educate the Germans to a new community, which in all its parts will be moved and animated by the same unified disposition $[1,66]$. Free will, according to Fichte, should be eradicated and, on the contrary, education should "create an acute need for decisions of the will, which cannot be opposed" [1, p. 71]; education, according to Fichte, should become "the reliable and deliberate art of forming in a man a solid and infallible goodwill" [1, p. 73].

The task of education, as defined by Fichte, is of national importance and should be a public policy pursued through a university that educates a patriotic citizen: "The love of the Fatherland itself should govern the state. It should also govern the state in the respect that it is the state that sets it a higher goal than preserving domestic peace, property, personal freedom, life, and well-being of all. [1, 199].

From the point of view of the German classics, as we have shown in the previous presentation, there is no contradiction in the named double task: the formation of humanity and the upbringing of a citizen, which (here it is possible to refer not only to romantics, but primarily to I. Kant, the successor and true interpreter of whose teachings Fichte considered himself), having as a "substratum" a free autonomous subject, it is acquired only in the form of a citizen; the analogy is almost obvious; just as culture has a state in its form, so humanity, brought into its form by education, is civicism. So: the university is the place of citizenship education; nationality, culture, state, university are thus brought into an essential connection.

However, the German Romantics have already disturbed the equilibrium in this twofold task; their "primary" priority is the formation of humanity - the state as a "work of art" is one of the areas in which humanity, while playing, realizes itself.

The classical university "died in 1890" (Heidegger). In the early twentieth century, attempts at "revival" and "reform" had, in Heidegger's words, no basis other than a "lack of reflection" and "interest" of the "scholarly estate" in maintaining prestige and participation in power. However, the "death of ideas" has its own "order" and "pattern": the necessity of the connection between the university and the state/culture/nation had to be removed - the liberal interpretation of the Kantian representation of the subject solved this problem in its own way. There is much less in common than in the difference between the absolute subject of German classical philosophy and the autonomous individual of "liberal metaphysics," although both representations are based on Kantian teaching; the autonomous individual is presented in its present given: it is not duty and necessity of internal law, but interest and compromise that justify commonalities as associations in "liberal metaphysics." The identities of culture and nation appear to be the result of identification based on the individual choice of the subject motivated by interest; the state is based on civic loyalty to the political order, i.e. conditioned by the ability of such an order to accommodate and reconcile private interests.

The idea of the classical university in such a perspective has no basis and is discredited; its mission is understood quite differently, the point is also that modernity, as defined by M. Heidegger, provides a basis for such an assessment of the idea of the classical university. 


\section{Discussion of Results}

The possibility of multiculturalism and multicultural politics $[9 ; 10]$ as equal rights and peaceful coexistence within the boundaries of the unified political order is revealed exclusively in the horizon of the culture as "cultural politics" (M. Heidegger); here, the distinction between "artistic creation" and "cultural artifact" and the statement that "the great eras of history have never "had" or "made" culture $[11,341]$ may be considered as the beginning. Its connection with the sacred constitutes the artistic creation; the severance of this connection turns the work of art into a commodity, no different from any other (such as education or human capital). Culture is a contemporary phenomenon, the "organization of experience" of the individual and the production of "cultural artifacts" for the market; it is a specific "sphere of production" in which, among other things, the "historiographical recounting of the past" is performed to "transfer" the artistic creations of the past to the present and provide the subject with an object for his "experience" and "aesthetic enjoyment".

The following is of fundamental importance for our presentation. First, culture is understood as a plastic (historically conditioned) set of features, devoid of substantiality (connection with the sacred, "religion", which also appears to be a "cultural feature", "cosmological value" which, according to D. Lala [12], follows to distinguish from "material values", always universal for all humankind and, unlike "cosmological", rational in a specific sense: defined through interest); the rational choice of an autonomous individual determines a "set" of "cultural characteristics", which he accepts and can change (like "the European's preference for exotic Chinese cuisine") at his own discretion [13]. In this respect, the concept of the "intersectional consensus" of J. Rolz [14], whose basic statement is the statement that individuals inhabiting one "political space" have more and more things in common than those that divide them and that what divides them can be reconciled, for example, in the process of compromise (F.R. Ankersmith [15]), makes sense; multiculturalism is a process of such reconciliation. Secondly, national cultures, as Heidegger observed already in the 1930s, have not simply turned into "ethnographic phenomena" but are essentially built into production and sold as marketable goods (for example, to "city-dwellers" who go to the "countryside" as tourists on weekends and wish to enjoy "folklore festivals"). This is a very far view from the one from which Fichte proceeded when defining "culture as destiny".

The modern university where "people from different cultures" study together 16] is thus no longer in the Fichtean sense a "place" and "center" of national culture as a necessary form of becoming, in reality, an absolute subject, but an enterprise producing "cultural people" as "historiographical animals" in the Heideggerian sense.

Liberal thought allows for the legitimacy of the "political nation" only as a "civic association" united by civic loyalty [18; 19]; nations defined through culture, as it was with Fichte, and even more so "ethnic nations" are evaluated simultaneously as a "relic of the past" and as a "mistaken idea", an "error" to be corrected and the "relic" to be eliminated. The national university is precisely among the "remnants" that have no place in the globalizing order of modernity; the task of the modern university is not to form a patriot, as Fichte insisted, but a citizen loyal to the global order and to "universal human" values.

Finally, the state, for whose service the national university has to prepare students, according to Fichte, is removed in the global political order, either through the formation of "cross-border communities" (not necessarily political, but always having power), or as Z. Bauman writes [20], through "redefining the tasks" set before the former modern state by the new global power: the state becomes a "police station" maintaining the global order at the local level in accordance with the universal rules and providing democratic legitimacy to the power [21]. 
Again, the university is seen as one of the instruments through which the global order is asserted [22], and as the place in which loyalty to the global order, i.e. the "cosmopolitan worldview" $[23 ; 24 ; 25]$, represented in the liberal economic paradigm and constituted in the horizon of the foundations of "liberal metaphysics," is to be defined as we conclude our outline of what it means.

One of the first to enquire into the "fate of the university" in the "age of globalization" was B. Ridings in "The University in Ruins" [26]. His study of the impact of globalization on "university transformation", far from being absolutely optimistic, led to a definition of the modern university as a corporation; since then, much has changed: demonstrative optimism has steadily increased, and reform is thought to be necessary and presented as a purely technical task. Ridings believes the purpose of his study is to "make a structural diagnosis of the contemporary transformations of the institutional function of the university" $[26,11]$, which are taking place under the defining influence of globalization, arguing that the contemporary representation of globalization is essential "Americanization": "Globalization is not a neutral process in which Washington and Dakar participate equally" [26, 11]; in this regard, the Heideggerian claim of the 1930s that modernity is Americanism, which, in turn, is the pushing to the limit of the definition of modernity by the idea of technology, should be considered. Ridings states "the collapse of the cultural mission of the university" [26, 12], "the separation of higher education from the nation-state" $[26,13]$, claims that the "enlightenment project" of the classical university has ended, all of which are the subjects of this article (but from a different perspective than Ridings). In the context of globalization, the university ceases to be an "ideological apparatus of the nation-state" [26,30] and becomes a "relatively independent bureaucratic system" [26, 30] with global objectives. Monocausal logic of capital (S. Žižek [27], U. Beck [5]) determines that the university is essentially a corporation included in the global market aimed at making a profit: "The university is increasingly turning into a bureaucratically organized and relatively autonomous consumer-oriented corporation" [26, 25]. Moreover, this corporation is initially conceived as transnational and global: the goods it produces and trades in the world market must be competitive: these goods are standardized education aimed at training specialists as human capital, and the production of practically oriented, technical, scientific knowledge. The form of organization of the university, which has become an element of the global network of the "world educational space", implies not only the "exchange" of students and constant "movement" of teachers but precisely - a single standard operating in a single space. Of course, this is an "idealtypical representation"; to the extent that the global order is constructed in the interests of [28; 29] what is called the "global community", i.e. the core of the global order, the university is tasked with ensuring that such an order is maintained and the benefits of those "included" in that "core": the "market logic" is thus limited to the political task.

Strictly speaking, if we bear in mind that the concept of "sustainable development" was originally designed for global order and believed the creation and maintenance of such order as its main goal (the fact that it is hierarchically organized is assumed "by default"), then the conclusion becomes obvious: a classical university is incompatible with the sounderstood "sustainable development" - on the contrary, a university-corporation is one of the institutions that ensure the achievement of "sustainable development" in the field of education (which, as we see, is also understood to be significantly different from what was understood by German romantics and classical German philosophy, which defined the idea of a classical university) [30]. 


\section{Conclusion}

What bore the name of "university of reason" and what is called "university-corporation" differ significantly: the common name "university" here is in the exact sense only a "technical term" meant to create the appearance of continuity and development in public discourse. Both "ideas" and "missions" of these two "phenomena" are totally different, only one of which is a necessary "element" of the reality represented in the economic paradigm. The university-corporation is a factory for the production of technical knowledge and human capital, which is put on the market and traded on a par with other commodities: The "logic of capital" is total and universal, and no "politicization" (U. Beck [5; 23]) is able to change it, but maybe only to limit it. In this regard, the UN GC Declaration, adopted on September 25, 2015, titled "Transforming our world: the 2030 Agenda for Sustainable Development" [31], one section of which is devoted to defining "goals for education", is one of the instruments of such "politicization": without questioning the goals of education, it declares how necessary differences, including inequalities, can be mitigated and partly limited, if not overcome.

We have undertaken to refrain from evaluating, among other things, the nature and type of necessity that led to the "death of the university" and the triumph of the "universitycorporation"; but a recollection of the "university of reason", its idea and mission may be of practical use: as a certain "ideal type" (in the sense of M. Weber [32]), a comparison with which may contribute to understanding what the "modern university" is, and the modernity in which its necessity is justified.

\section{References}

1. I. G. Fichte, Speeches to the German Nation, 350 (St. Petersburg: Nauka, 2009)

2. V. fon Humboldt, Language and Philosophy of Culture, 450 (Moscow: Progress, 1985)

3. H.-G. Gadamer, Truth and Method: Foundations of Philosophical Hermeneutics, 704 (Moscow: Progress, 1988)

4. M. Heidegger, Reflections VII-XI (Black Notebooks 1938-1939), 528 (Moscow: Gaidar Institute Publishing House, 2018)

5. W. Beck, What is Globalization, 304 (Moscow: Progress-Tradition, 2001)

6. A. Schutz, Selected: A world glowing with meaning, 1056 (Moscow: "Russian Political Encyclopedia", ROSSPEN, 2004)

7. R. Barnett, Recapturing the Universal in the University. EPAT 37(6), 785 (2005).

8. I. Kant, The Founding of the Metaphysics of Morals in I. Kant. Works in eight volumes 4, 153 (Moscow: Choro, 1994)

9. R. Maciel, The Future of Liberal Multiculturalism. PSR 12(3), 383 (2014)

10. M. Nye, The Challenges of Multiculturalism. Cult Relig 8(2), 109 (2007)

11. M. Heidegger Nietzsche, In 2 volumes 1, 608 (St. Petersburg: Vladimir Dal, 2006)

12. D. Lal, Praise of the Empire: Globalization and Order, 364 (Moscow: New Publishing House, 2010)

13. L. L. Lomako, K.G. Maltsev, Eurasian Law J. 3, 485 (2021)

14. J. Rowlsü, Political Liberalism, 525 (New York: Columbia university press, 1996)

15. F.R. Ankersmit, Aesthetic policy. Political philosophy beyond fact and value, 432 (Moscow: Publishing House of the State University Higher School of Economics, 2014) 
16. V. Harris, M. Kumaran, H. Harris, D. Moen, Compare 49(3), 430 (2019)

17. C. Chin, Nations and Nationalism, 27(1), 112 (2021)

18. L.L. Lomako, K.G. Maltsev, Kant, 3(36), 145 (2020)

19. A. L. Alaverdyan, K. G. Maltsev, News of higher educational institutions. North Caucasian region. Social Sciences, 4 (208), 4 (2020)

20. Z. Bauman, Globalization. Consequences for individuals and society, 188 (Moscow: Ves Mir Publishing House, 2004)

21. K.G. Maltsev, L.L. Lomako, Bulletin of the Leningrad State University named after A.S. Pushkin, 1, 55(2020)

22. D. Lehner, J. Wurzenberger, Campus-Wide Information Systems, 30(5), 358 (2013).

23. W. Beck, Cosmopolitan Worldview, 336 (Moscow: Center for Research on PostIndustrial Society, 2008)

24. D. Swanson, M. Gamal, Globalisation, Soc. 30, 1 (2021)

25. A. Blok, S. Selchow, Glob Netw (Oxf), $20(3), 489$ (2020)

26. B. Readings, The university is in ruins, 299 (Moscow: Publishing house of the Higher School of Economics, 2010)

27. S. Zizek, About violence, 184 (Moscow: Europe Publishing House, 2010)

28. J.A. Scholte, The World Economy, 31(11), 1471 (2008)

29. K. Hack, J. Imp. Commonw. Hist. 47(5), 818 (2019)

30. S. Bengtsson, L. Östman, Environ. Educ. Res. 22(1), 1 (2016)

31. Transforming Our World: The 2030 Agenda for Sustainable Development. https://www.un.org/sustainabledevelopment/ru/about/development-agenda/

32. M. Weber, Basic Sociological Concepts in M. Weber. Selected Works, 602 (Moscow: Progress, 1990) 